\title{
A mass-like lesion encasing the aortic arch and descending aorta: immunoglobulin G4-related periaortitis
}

\author{
Chewan Lim ${ }^{1}$, Chul-Min Ahn ${ }^{1}$, Hyun-Chel Joo² ${ }^{2}$ Jung Yoon Pyo ${ }^{3}$, and Young-Guk Ko ${ }^{1}$
}

\author{
${ }^{1}$ Division of Cardiology, Department \\ of Internal Medicine, ${ }^{2}$ Division of \\ Cardiovascular Surgery, Department \\ of Thoracic and Cardiovascular \\ Surgery, Severance Cardiovascular \\ Hospital, Yonsei University College \\ of Medicine, Seoul; ${ }^{3}$ Division of \\ Rheumatology, Department of \\ Internal Medicine, Severance \\ Hospital, Yonsei University College \\ of Medicine, Seoul, Korea
}

A 68-year-old man was referred to our hospital owing to dyspnea and a low-attenuation mass-like lesion encasing the aortic arch extending to the descending thoracic aorta observed on chest computed tomography (CT) (Fig. 1A-1C).

He had experienced weight loss $(5 \mathrm{~kg})$ for 3 months. His initial vital signs were stable. The laboratory tests showed a normal complete blood count, elevated erythrocyte sedimentation rate (ESR; $120 \mathrm{~mm} / \mathrm{hr}$ ) and C-reactive protein (CRP) level ( $85 \mathrm{mg} / \mathrm{L})$, and a normal procalcitonin level.

Transthoracic echocardiogram and coronary angiography, including an aortogram, revealed no specific dyspnea-related findings (Fig. 1D). Additional laboratory tests were conducted for the differential diagnosis of infective diseases, rheumatologic diseases, hematologic diseases, and other malignancies.

The patient tested negative for an interferon-gamma releasing assay and viral and rheumatoid markers. The serum immunoglobulin $\mathrm{G}(\mathrm{IgG})$ and $\mathrm{IgG}_{4}$ levels were elevated at 2,021 and $247 \mathrm{mg} / \mathrm{dL}$, respectively.

Positron emission tomography showed intense fluorodeoxyglucose uptake in the mediastinal soft tissue infiltrative lesion (Fig. $1 \mathrm{E}$ and $1 \mathrm{~F}$ ). Incisional biopsy was performed (Fig. 2A and 2B). Pathological analysis revealed lymphoplasmacytic infiltration with fibrosis and an elevated $\mathrm{IgG}_{4}$ level (64 cells/high-power field) and $\mathrm{IgG}_{4} / \mathrm{IgG}$ ratio (82\%), suggestive of IgG4-related periaortitis (Fig. $2 \mathrm{C}$ and $2 \mathrm{D}$ ).

He was referred to the rheumatologic department; steroid treatment was initiated (prednisolone $20 \mathrm{mg}$ twice daily). At the first follow-up visit, his dyspnea had markedly improved, and the serum ESR and the CRP and $\mathrm{IgG}_{4}(124 \mathrm{mg} / \mathrm{dL})$ levels were normalized. Steroid therapy will be continued with follow-up CT after 3 months.

$\mathrm{IgG}_{4}$-related periaortitis is a rare autoimmune disease associated with systemic fibroinflammation. Early diagnosis using imaging modalities with histopathological confirmation is important to avoid irreversible organ damage requiring surgical or endovascular intervention, such as marked aneurysmal dilation or rupture of the aorta. This case suggests that IgG4-related periaortitis should be considered in patients with abnormal masslike lesions surrounding the aorta.

\section{Conflict of interest}

No potential conflict of interest relevant to this article was reported. 

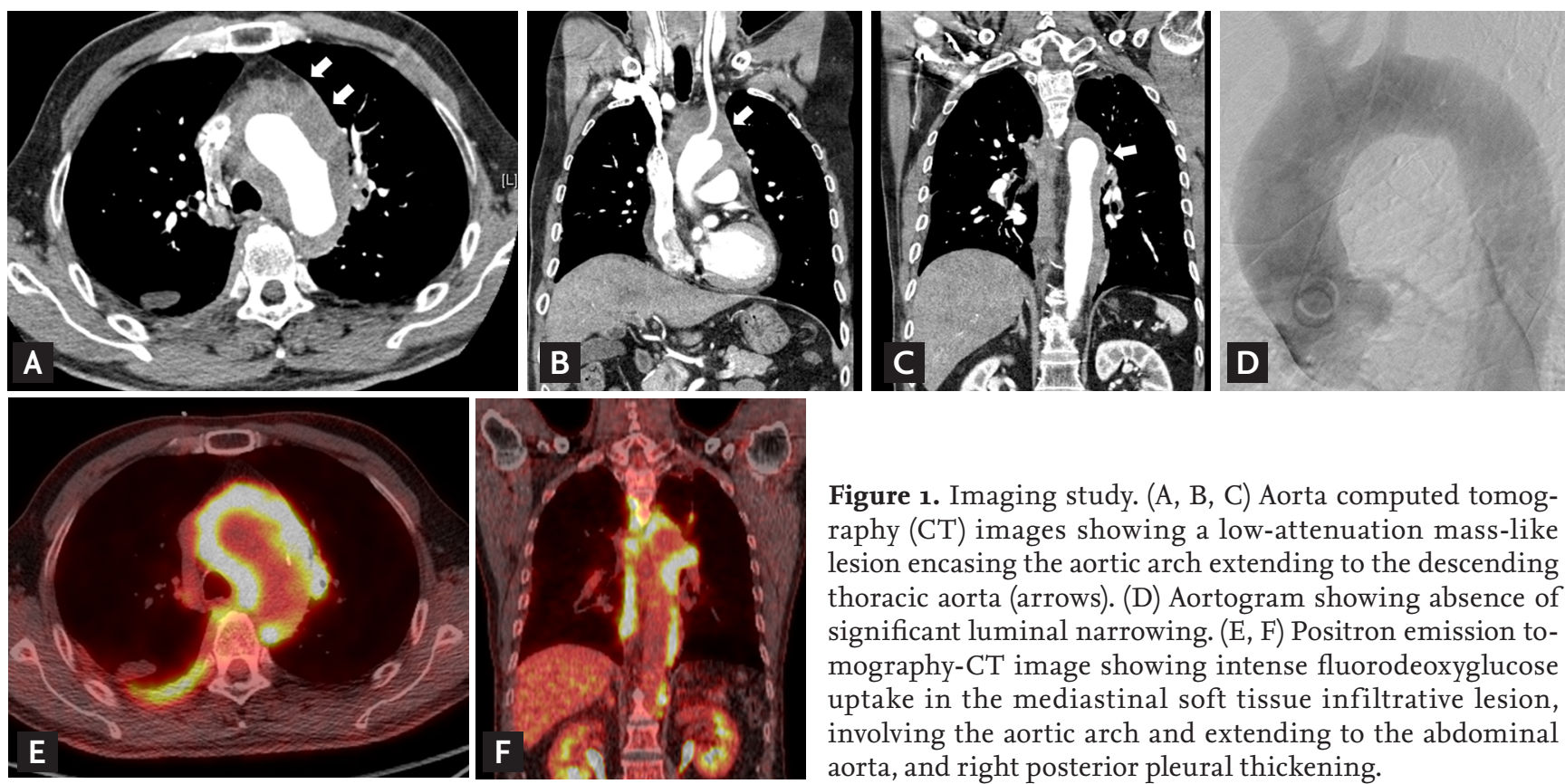

Figure 1. Imaging study. (A, B, C) Aorta computed tomography $(\mathrm{CT})$ images showing a low-attenuation mass-like lesion encasing the aortic arch extending to the descending thoracic aorta (arrows). (D) Aortogram showing absence of significant luminal narrowing. (E, F) Positron emission tomography-CT image showing intense fluorodeoxyglucose uptake in the mediastinal soft tissue infiltrative lesion, involving the aortic arch and extending to the abdominal aorta, and right posterior pleural thickening.
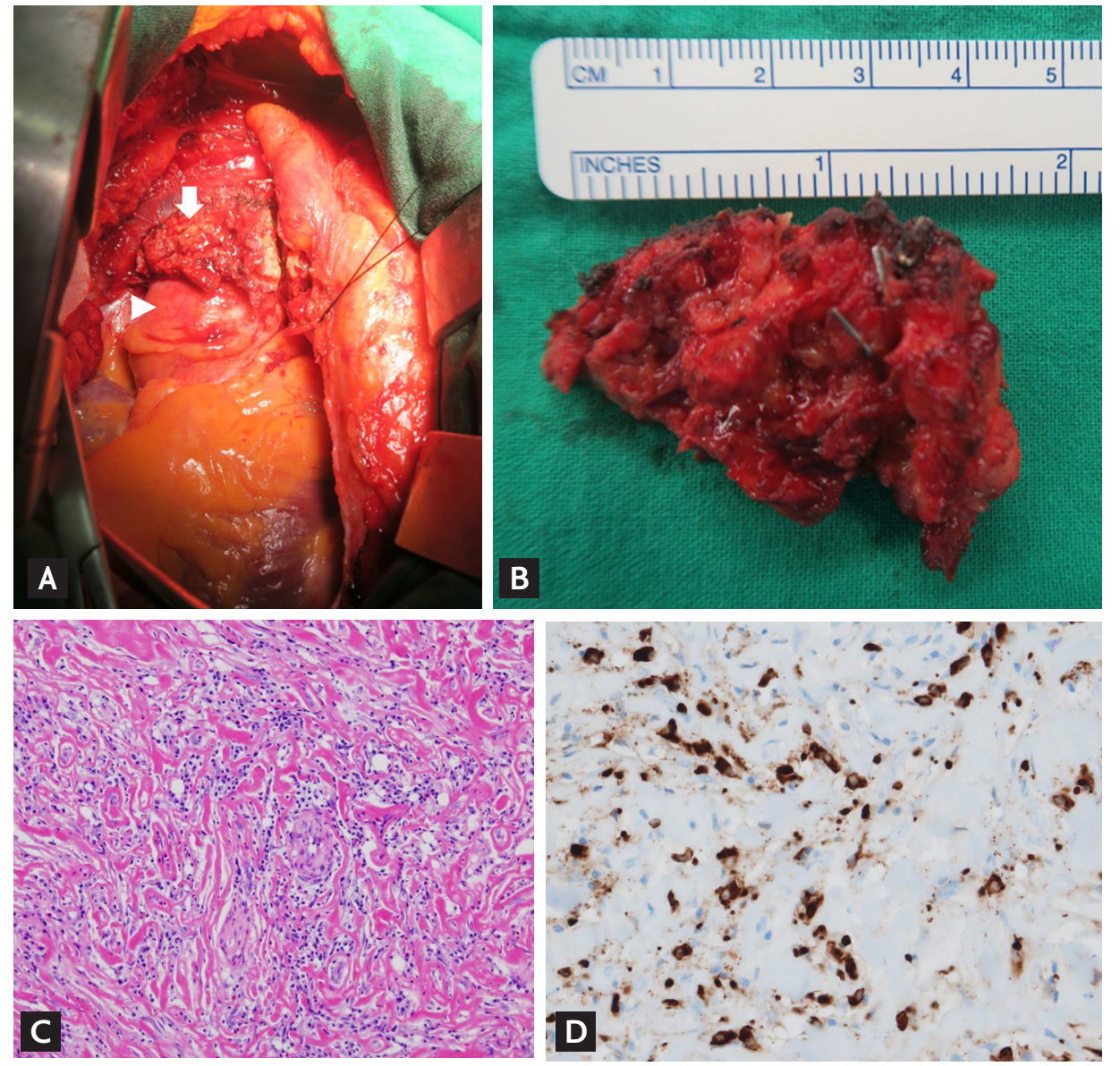

Figure 2. Tissue biopsy and histological analysis. (A) A dense and thick mass (arrow) is encircling the ascending aorta (arrowhead) and aortic arch. (B) Incisional biopsy is performed for tissue confirmation. (C) Lymphoplasmacytic infiltration with fibrosis is observed in the histological analysis image, suggestive of immunoglobulin $\mathrm{G}_{4}\left(\mathrm{IgG}_{4}\right)$-related disease (H\&E, $\times 100)$. (D) Immunohistochemical staining image showing multiple IgG-positive plasma cells, with an increased $\mathrm{IgG}_{4} / \mathrm{IgG}$ ratio of approximately $82 \%$ ( $>70 \%$ is strongly suggestive of IgG-4 related disease) (×200). 